\title{
Redescubrimiento de paisajes ganaderos tradicionales (Camero Nuevo, La Rioja) después del abandono rural y de la dinámica reciente de cambios de usos y cubiertas*
}

\author{
César López Leiva \\ Sergio González Ávila \\ Ramón Elena Rosselló \\ Universidad Politécnica de Madrid \\ cesar.lopez@upm.es \\ sergio.gonzalez@upm.es \\ ramon.elena.rossello@upm.es
}

Recibido: septiembre de 2019

Aceptado: diciembre de 2019

Publicado: abril de 2020

\section{Resumen}

Este artículo se concibe como un análisis y una reflexión en clave de presente, pero también como una dimensión prospectiva sobre el cambio en los usos del suelo y en los ecosistemas en los últimos setenta años, así como en el modelo tradicional de ocupación humana en Cameros (La Rioja), un territorio representativo de los paisajes rurales del norte de la península Ibérica vinculados, desde la época medieval, al sistema económico de la trashumancia. Centrándonos en la subcomarca de Camero Nuevo, analizamos algunos datos reveladores de los cambios de las unidades de uso y de la cubierta vegetal registrados desde 1956, y valoramos su trascendencia territorial, ecosistémica y paisajística desde una perspectiva actual, pero también proyectada al futuro. En este último sentido, planteamos la necesidad de realizar una revaloración de los signos ecológicos y culturales de sus paisajes y la conveniencia de profundizar en la orientación sostenible de los aprovechamientos forestales. Con el aumento del ecoturismo de origen urbano, subrayamos la necesidad de entender las diferentes estructuras del medio natural (arbolado, matorral, pastos) como parte de un tejido ecológico múltiple e integral, inseparable en cualquier caso, y a diferentes escalas y niveles, de la acción humana.

Palabras clave: paisajes ganaderos; abandono rural; cambios de usos y cubiertas; ecoturismo; ecología del paisaje

* La realización de este artículo se inscribe en el marco del proyecto CSO2015-6787-C6-4-P del Ministerio de Economía y Competitividad del Gobierno de España. 
Resum. Redescobriment de paisatges ramaders tradicionals (Camero Nuevo, La Rioja) després de l'abandonament rural $i$ de la dinàmica recent de canvis d'usos $i$ cobertes

El present estudi es concep com una anàlisi i una reflexió en clau de present, però també de futur, sobre el canvi en els usos del sòl i en els ecosistemes, així com en el model tradicional d'ocupació humana, esdevingut en els darrers setanta anys a Cameros (La Rioja), un territori representatiu dels paisatges rurals del nord de la península Ibèrica vinculats, des de l'època medieval, al sistema econòmic de la transhumància. Centrant-nos en la subcomarca de Camero Nuevo, analitzem algunes dades reveladores dels canvis de les unitats d'ús i coberta vegetal registrats des de 1956 i en valorem la transcendència territorial. En clau de futur plantegem, com a possibles línies d'acció, la revaloració dels signes ecològics i culturals en els paisatges suposadament naturals, dels aprofitaments forestals com a garants de la sostenibilitat i de la dinàmica evolutiva del paisatge, enfront del risc de les visions simplificadores o excessivament rígides. Amb l'augment de l'ecoturisme d'origen urbà subratllem la necessitat d'entendre les diferents estructures del medi natural (arbrat, matoll, pastures) com a part d'un teixit ecològic múltiple i integral, inseparable en qualsevol cas, i a diferents escales i nivells, de l'acció humana.

Paraules clau: paisatges ramaders; abandonament rural; canvis d'usos i cobertes; ecoturisme; ecologia del paisatge

Résumé. Redécouverte de paysages d'élevage traditionnel (Camero Nuevo, La Rioja) après l'abandon rural et la dynamique récente de changements d'usages et de couvertures

Cette étude est conçue comme une perspective analytique de Cameros (La Rioja), qui constitue un exemple représentatif des paysages ruraux du nord de la Péninsule Ibérique, liée depuis la période médiévale au système économique de la transhumance. Nous analysons (dans le contexte de la démarcation de Camero Nuevo) quelques données révélant des modifications des unités d'utilisation et de la couverture végétale enregistrées depuis 1956, et nous attachons de la valeur à son importance territoriale. Face à l'avenir, nous proposons, comme lignes d'action possibles, la réévaluation des signes écologiques et culturels dans les paysages naturels, l'utilisation de l'exploitation forestière en tant que garantie de la durabilité et de la dynamique évolutive du paysage - face au risque d'une vision simplifiée. Dans le contexte d'augmentation de l'écotourisme d'origine urbaine, nous soulignons la nécessité de comprendre les différentes structures de l'environnement naturel (arbres, broussailles, pâturages) en tant que partie intégrante d'un tissu écologique intégral et indissociable, à tous les niveaux et à différentes échelles, de l'action humaine.

Mots-clés: paysages de bétail; abandon rural; changements d'usages et couvertures; écologie du paysage

Abstract. Rediscovery of traditional grazing landscapes after rural abandonment and recent land use and land cover change dynamics: Camero Nuevo, La Rioja

This study is conceived as an analytical prospection on Cameros, La Rioja; a representative example of rural landscapes in the northern Iberian Peninsula linked from the medieval period to the economic system of transhumance. We analyze some data (specifically on the Camero Nuevo district) that reveal changes in the units of use and vegetation cover registered since 1956, and assess its territorial importance. With a view to the future we propose, as possible lines of action, the re-evaluation of ecological and cultural signs in the natural landscapes, the use of forest management as a guarantee of sustainability and of the evolutionary dynamics of the landscape-to avoid the risk of simplifying views. As regards the increase 
in urban-based ecotourism, we underscore the need to understand the different structures of the natural environment (trees, brush, pastures) as part of an inseparable, multiple and integral ecological fabric at different scales and levels from the perspective of human action.

Keywords: grazing landscapes; rural abandonment; land use and cover changes; ecotourism; landscape ecology

\author{
Sumario \\ 1. Introducción 4. Discusión \\ 2. Material y métodos 5. Conclusiones \\ 3. Resultados Referencias bibliográficas
}

\title{
1. Introducción
}

A partir de 1939, el geógrafo Troll incluye el concepto de paisaje como nivel de organización ecológica. Su concepto del paisaje ecológico deja de ser antropocéntrico, dado que sus causas no son necesariamente las actividades humanas, y sus destinatarios son la totalidad de seres vivos que habitan un territorio. Desde entonces la ecología del paisaje (Forman y Godron, 1986) ha tenido un desarrollo exponencial ayudado por el enorme avance tecnológico en la adquisición y procesado de información geográfica, que permiten la disposición de información muy objetiva, cobertura completa, alta resolución y frecuencia elevada. En la actualidad, ambos enfoques están teniendo un amplísimo desarrollo, ya que su armonización es imprescindible para lograr una gestión territorial sostenible. En este artículo se van a valorar los paisajes desde ambas perspectivas, poniendo de manifiesto las concordancias y las divergencias en paisajes españoles muy representativos.

Durante el siglo xx, en España, los procesos de despoblación rural y crecimiento de las concentraciones urbanas han sido intensos y continuados. Estos procesos han tenido una gran trascendencia sociológica, puesto que han provocado cambios radicales en las formas de valorar y manejar los paisajes rurales, que poco a poco se han ido impregnando de un predominante ecologismo de origen urbano. Por ello, la gestión del medio rural, políticamente condicionada por los movimientos sociales de raíz urbana, ha generado y genera unas realidades paisajísticas altamente polarizadas. Mientras que los paisajes periurbanos pierden sus elementos estructurales rurales, los paisajes menos accesibles y agrológicamente peores van cambiando de ser culturales a pseudonaturales. De esta forma, el abandono de los usos tradicionales es el precursor de la aparición de paisajes relativamente nuevos, los cuales son altamente valorados dentro del nuevo paradigma socioecológico actual.

Extensas comarcas montañosas españolas son hoy en día reconocidas por mostrar ejemplos paradigmáticos de paisajes estables y perdurables en los que 
predominan los sistemas boscosos de elevada biodiversidad y aparente escasa intervención humana, entre los que se encuentran los de la subcomarca de Camero Nuevo. Pero si se profundiza más allá de las estructuras actuales, se comprueba que, en un pasado reciente, fueron unos paisajes muy transformados por una actividad ganadera potente y persistente durante siglos. Así, la ganadería constituye la base esencial de su patrimonio cultural, lo que se percibe a través de múltiples rastros etnográficos, arqueológicos, toponímicos, fitosociológicos, palinológicos, etc.; incluso cuando, como en nuestros días, ese trasfondo ha quedado oculto y en parte borrado tras las vicisitudes históricas que han provocado la proliferación de la vegetación arbolada. Sin el conocimiento de esas vicisitudes, la interpretación y la evaluación del paisaje actual, y por tanto la realidad percibida del mismo, quedarían claramente limitados y simplificados.

En consecuencia, desde nuestra interpretación, la valoración patrimonial del paisaje debería incluir rasgos históricos que enriquecieran los análisis ecológicos y limitaran los sesgos surgidos del paradigma socioecológico urbanícola. En este artículo abordamos la evolución histórica de la estructura de un paisaje rural, el de Camero Nuevo, enfatizando la importancia que ha tenido la ganadería (a través, fundamentalmente, del aprovechamiento extensivo de sus pastos) en su conformación como paisaje cultural. Nuestro análisis y posterior reflexión llevados a cabo en este trabajo parten de la constatación de que durante la segunda mitad del siglo xx, en España, han proliferado paisajes duales que presentan aparente estabilidad e inmutabilidad, pero que históricamente han estado sometidos al aprovechamiento continuado de sus recursos forestales y, sobre todo, ganaderos. Así, a través de un caso de estudio, pretendemos mostrar el interés de las aportaciones del análisis histórico y de los cambios estructurales a la valoración de los paisajes y su patrimonialización. Para ello verificamos la existencia de estos hipotéticos cambios en un paisaje definido e indagamos sobre la causalidad y las consecuencias de los procesos detectados.

Los objetivos concretos son:

1. Sintetizar la historia de los factores determinantes modeladores de los paisajes de Camero Nuevo desde la Edad Media hasta la primera mitad del siglo Xx.

2. Detectar y evaluar cuantitativamente cambios ocurridos en los paisajes durante el periodo que comprende los años 1956 a 2014.

3. Reflexionar acerca de las premisas con que debe plantearse la valoración patrimonial de los paisajes de larga tradición ganadera desde la perspectiva de su redescubrimiento ecoturístico por parte de sociedades de origen urbano.

\section{Material y métodos}

Este artículo se ha escrito a partir de la información documental disponible de un ente territorial que presenta las características representativas del paisaje de 
las comarcas montañosas del sistema Ibérico septentrional. Metodológicamente se diseña como un «caso de estudio» de la subcomarca del Camero Nuevo.

\subsection{Zona de estudio}

La subcomarca del Camero Nuevo (parte más occidental de la gran comarca de Los Cameros riojano-sorianos) se sitúa en La Rioja montañosa centrooccidental (figura 1). Coincide en buena medida con la cuenca del río Iregua, desde su cabecera en Sierra Cebollera hasta su paso por el contrafuerte de los mallos de Viguera. Su superficie total es de casi 52.000 hectáreas y su población supera escasamente los 2.000 habitantes (2011), repartidos en 13 municipios (la Hermandad de las Trece Villas mancomunadas históricamente para el aprovechamiento de los pastos en montes de la sierra). La delimitación de términos municipales no ha experimentado grandes cambios desde la Edad Media, aunque en el último tercio del siglo xx desaparecen algunas aldeas.

Constituye un territorio representativo de transición climática y fitogeográfica entre el ambiente subatlántico y el mediterráneo. Las actuales cubiertas arboladas (pinares, hayedos, robledales, encinares y acebedas subarbóreas) son predominantes, y al menos la mitad de su superficie de distribución alcanza rangos de porcentaje de cabida cubierta mayores del 35\%. Esas masas boscosas proporcionan un alto valor escénico en un entorno ambientalmente heterogéneo, dada la intrincada fisiografía de los cerrados valles tributarios del Iregua. Otros tipos de formación se intercalan en el mosaico junto con peñas rocosas y canchales de derrubio («desecadas»): matorrales (enebrales, piornales y brezales de altura, espinares y setos caducifolios, bujedos, brezales y biercolares,

Figura 1. Delimitación de Camero Nuevo y su localización en La Rioja

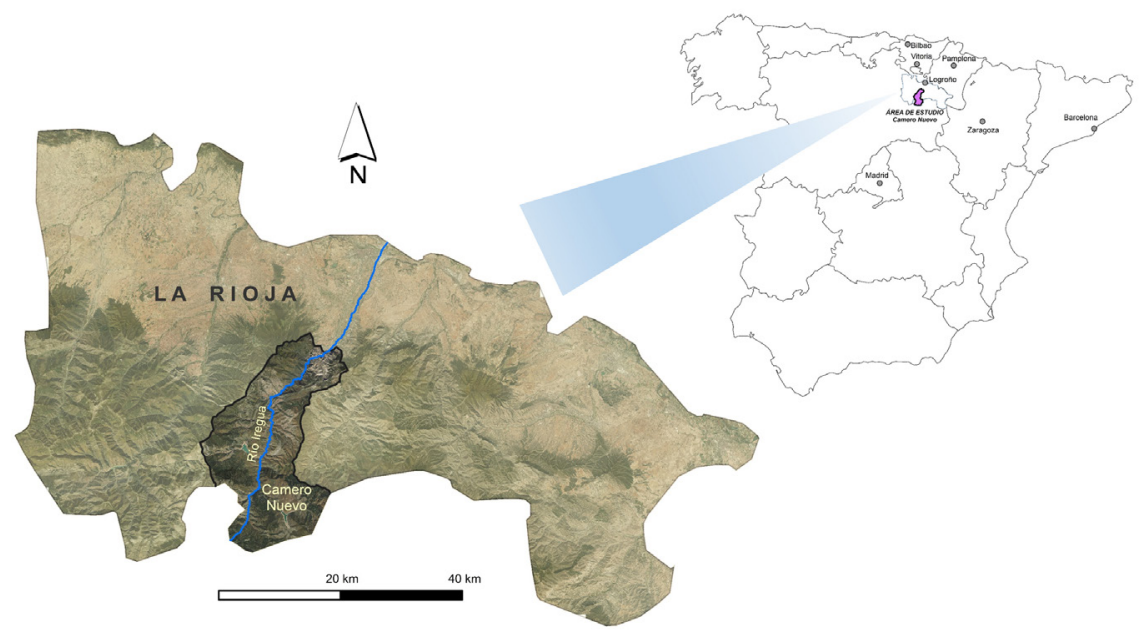

Fuente: elaboración propia. 
Figura 2. Cultivos arbóreos (olivares, almendrales) en las faldas de las peñas rocosas del contrafuerte septentrional de la subcomarca de Camero Nuevo, en el entorno de Viguera y Castañares de las Cuevas

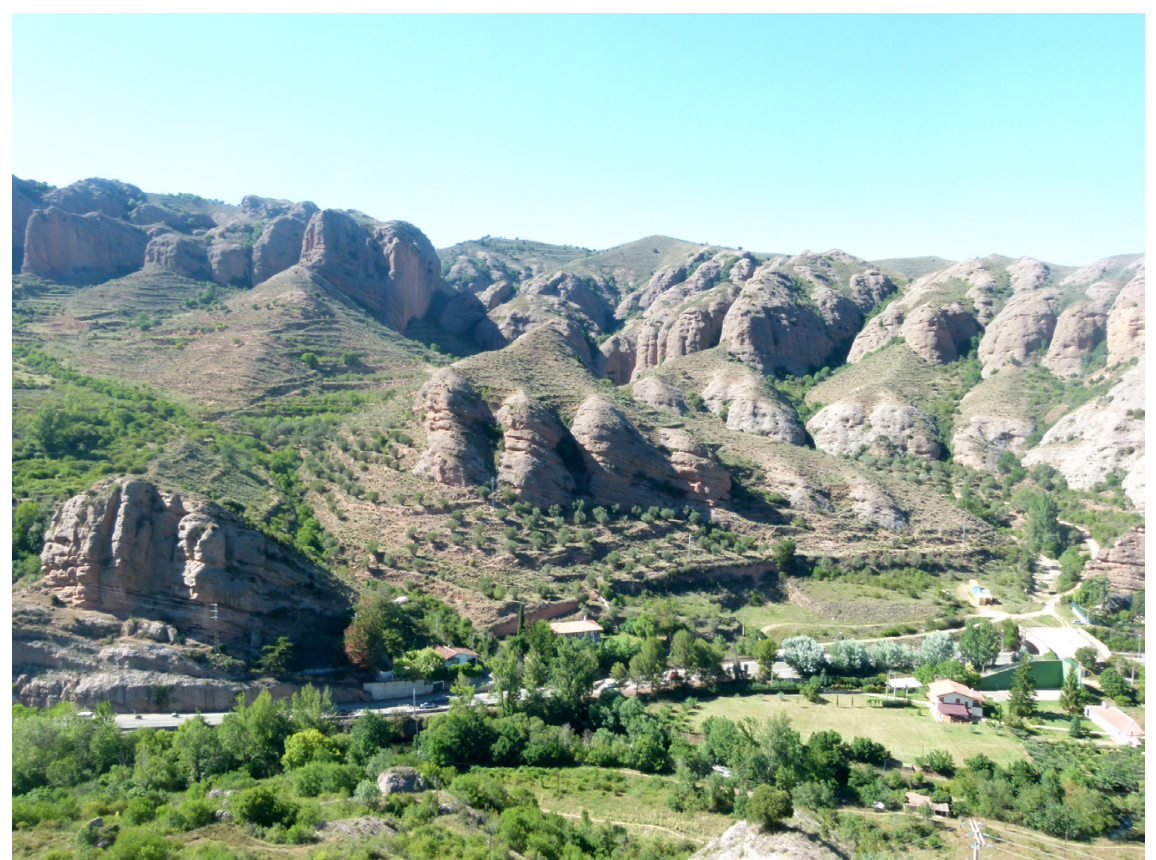

Fuente: autores.

escobonales, lasto-timo-aliagares) y pastos herbáceos (cervunales, prados de diente, pastos mesófilos y estacionales) (López Leiva, 2018). Además, sobre todo en el sector septentrional, se emplazan cultivos tradicionales con alto valor patrimonial (figura 2).

En lo que respecta al patrón espacial general de la población humana, el territorio en su conjunto aparece salpicado de núcleos habitados y de pequeñas aldeas, algunas de las cuales se encuentran actualmente despobladas.

En el caso particular de Cameros, la presencia controlada de herbívoros y las quemas pastorales son clave para explicar el trasfondo histórico del mosaico vegetal, así como también, en las masas arboladas, los tratamientos selvícolas, que determinan fisonomía, estratificación y componentes principales.

\subsection{Métodos aplicados para la evaluación de la dinámica del paisaje}

El análisis de la evolución reciente del paisaje se ha realizado previa cuantificación y análisis de los tipos de uso y cubierta vegetal (TUC) en Camero Nuevo, en los dos años de inicio y final del periodo estudiado: 1956 y 2014, respectivamente. Para ambas fechas se fotointerpretaron imágenes aéreas de 
1956 («vuelo americano») y 2014 (PNOA), utilizando una unidad mínima cartografiable de 1 hectárea. Las capas resultantes son modelos de la estructura del paisaje en las dos fechas de estudio. Estas capas fueron generadas y procesadas utilizando ArcGIS 10.3, de forma que se obtuvieron los porcentajes de todas las categorías (TUC) de elementos superficiales del paisaje considerados (teselas). Además, las capas de los modelos de paisaje se analizaron de forma cuantitativa, con el fin de proporcionar información esencial para describir e interpretar los procesos de cambio, tanto en lo que respecta a las cubiertas vegetales como a los tipos de uso del suelo.

Para este estudio de Camero Nuevo se utilizó una adaptación de la metodología (Benito González et al., 2017) desarrollada en SISPARES (Sistema de Seguimiento de los Paisajes Rurales Españoles) (González Ávila y Elena Rosselló, 2009; Gómez-Sanz et al., 2014). Los TUC definidos en SISPARES fueron adaptados a las características de la comarca estableciendo una nueva clasificación de subtipos. El criterio utilizado para definir los subtipos es la presencia de arbolado, identificada por su Fcc (fracción de cabida cubierta). El registro de este atributo estructural para las teselas identificadas por fotointerpretación experta, tanto sobre los fotogramas más antiguos disponibles como sobre ortofotos recientes, permitió caracterizar y cuantificar la evolución de la cobertura arbolada en el período de los casi 70 años transcurridos desde el año inicial. Con carácter específico para este territorio, se establecieron tres niveles de densidad de arbolado en las teselas, estimada a través de la Fcc: 0-35\% (arbolado escaso), 35-65\% (arbolado abierto) y 65-100\% (arbolado denso). Los dos últimos intervalos son considerados bosque (B), mientras que el primero se corresponde con tipos no arbolados: matorral (M), cubierta herbácea $(\mathrm{P})$ y roquedos y canchales $(\mathrm{L})$. La asignación de TUC y subtipos se basa en la fisonomía general (por ejemplo mediante la presencia o la exclusividad de leñosas y/o herbáceas) y la presencia de arbolado, cuantificada según los siguientes rangos en el caso de TUC que no sean bosque: Fcc 0-15\% o 15-35\%. Finalmente, se llevó a cabo una valoración de los cambios en base a la clasificación de valoración de los TUC y de los subtipos (tabla 3), cuya ordenación realizamos según su grado de naturalidad, complejidad estructural y cantidad de biomasa.

\section{Resultados}

\subsection{Relato histórico de la evolución paisajistica}

La historiografía de los usos y de los aprovechamientos humanos de la Tierra de Cameros nos revela el papel determinante que han tenido las actividades ganaderas en la dinámica de la vegetación y por tanto en su paisaje (tabla 1). 
Tabla 1. Síntesis de la evolución histórica de los usos y cubiertas del suelo en Camero Nuevo

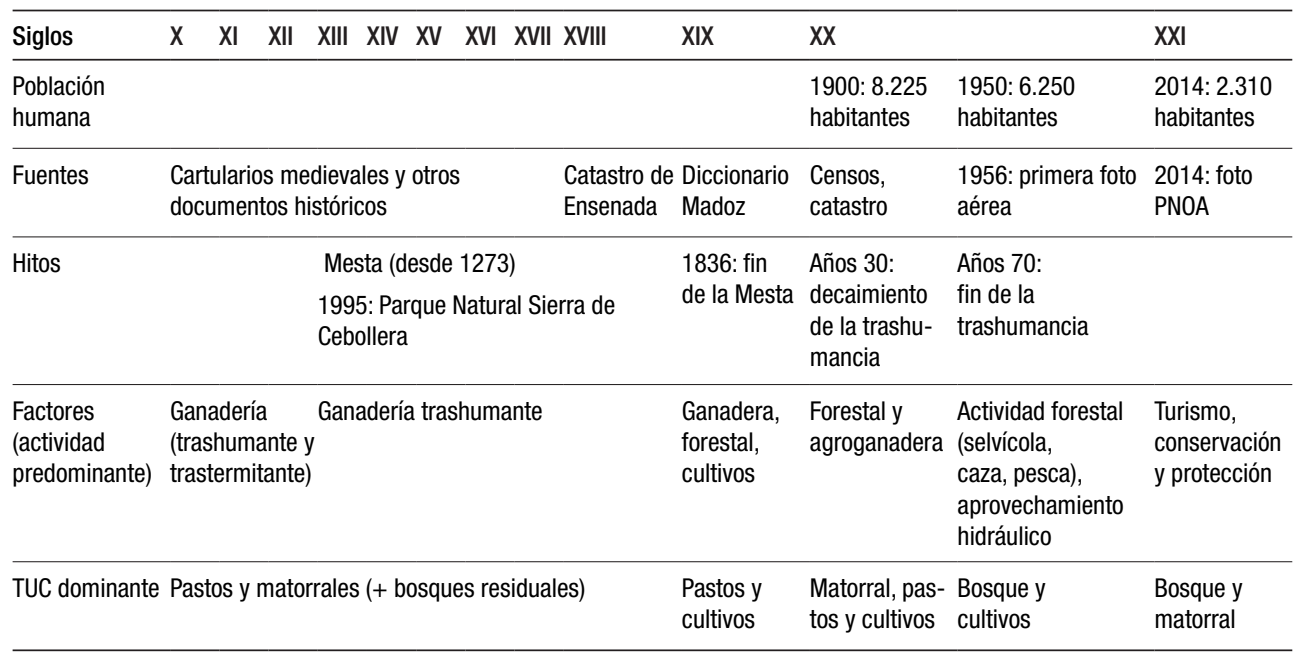

Fuente: elaboración propia.

Desde el siglo x se constata la existencia de trashumancia en la comarca (Elías Pastor et al. 1992). En época de la Reconquista se incrementó la intensidad del pastoreo en las montañas riojanas, al tiempo que se redujo la actividad ganadera trashumante, afectada por los episodios bélicos que eran frecuentes en los valles agrarios durante varios siglos.

Una vez conquistadas Córdoba (1236) y Sevilla (1248), la frontera musulmana se establece al sur del Guadalquivir. Ello permite que la trashumancia se implante a escala peninsular, puesto que se conectan las montañas Béticas y Mariánicas con las Ibéricas y Cantábricas mediante vías pecuarias. En apoyo a esta actividad nómada, en 1273, el Honrado Concejo de la Mesta permite el esquilmo libre de pastos. Con estos privilegios, la economía de la comarca se cimentó definitivamente en la ganadería. Sus pastos constituyeron "extremos" de vías pecuarias (cañadas reales) para ganado ovino mesteño, cabrío y algo de vacuno. Los aprovechamientos eran comunales, en regímenes de origen germánico (Elías Pastor et al., 1992). Como actividad derivada floreció la fabricación de paños, que, hasta pasado el siglo XVIII (Andrés Cabello, 2008), conllevó un notable incremento de población.

El pastoreo y las quemas para regenerar los pastos alteraron la cubierta vegetal espontánea: los montes arbolados se quedaron reducidos en extensión o se simplificaron, puesto que perdieron espesura y diversidad; el fuego recurrente favoreció la persistencia de especies rebrotadoras (hayas, robles, encinas y otras frondosas) en detrimento de las que no lo eran (pinos), como subrayan Díaz-Fernández et al. (2004).

Con una menor ocupación superficial, los cultivos agrícolas se concentraban en las proximidades de los núcleos de población instalados en los fondos 
de los valles. A partir del siglo xvi fue frecuente la roturación, a menudo con abancalamiento de tierras con fuertes pendientes. En los «enclavados» se quemaba y se roturaba directamente una porción del monte, que se cultivaba durante 2 o 3 años cada 20 (Lasanta y Errea, 2001).

Reinando Carlos III, los privilegios de la Mesta fueron parcialmente derogados y se suprimieron en 1836. Comenzó entonces un declive paulatino: en el conjunto de La Rioja se fue reduciendo el censo ovino de las 500.000 cabezas estimadas en la segunda mitad del siglo XviII hasta dos tercios de esa cantidad un siglo después (cifra que se mantuvo, aunque decreciente, hasta la década de 1960).

A finales del siglo XVIII aún se computaban 130.000 ovejas trashumantes en varios términos de Camero Nuevo, pero durante los cuarenta últimos años del siglo Xx se redujo a la mitad del censo inmediatamente precedente (Elías y Muntión, 1989; Moreno Fernández, 1996). En Camero Nuevo, que no fue excepción sino núcleo principal del descenso, antes de la Guerra Civil solo quedaban rebaños trashumantes en cuatro términos: Villoslada, Lumbreras, El Rasillo y Ortigosa (Elías Pastor et al., 1992). Un 50\% de los telares que registraba el Catastro de la Ensenada en el siglo XviII había desaparecido cien años después (Madoz, 1845-1850).

Con las desamortizaciones del siglo XIX se enajenaron propiedades, aunque en Camero Nuevo se exceptuaron bastantes montes gracias a su catalogación como públicos. La superficie de los Montes de Utilidad Pública del Catálogo de 1859 (ICONA, 1990), llegaba a las 26.700 hectáreas en Camero Nuevo, de las cuales las masas arboladas tenían como dominantes principales hayas (Fagus sylvatica), robles (Quercus pyrenaica, Q. faginea), encinas (Q. ilex) y, en menor medida o más localizados o secundarios, pinos (Pinus sylvestris). Hasta finales del siglo XIX y entrado el xx, el rasgo dominante en el paisaje era la mayor proporción de superficie desarbolada (matorrales, pastos).

La decadencia de las cabañas estantes y trashumantes y del comercio de la lana, con algunos repuntes transitorios, fue acompañada de un declive demográfico paulatino: la población de Camero Nuevo en 1950 era de 6.250 habitantes y un decenio después, de 5.192. La actual ha disminuido un $56 \%$ respecto a la existente al iniciarse la década de 1960 y un $72 \%$ en relación con la de 1900, que llegaba a 8.225, según se deduce de Goerlich Gisbert et al. (2015).

\subsection{Cuantificación de los tipos de uso y cubierta vegetal en Camero Nuevo}

En 2014, el arbolado con diferentes rangos de cobertura (mayor del 35\%) cubría casi 25.000 hectáreas, lo que suponía un 50\% del total comarcal (51.971,17 hectáreas) (tabla 2).

En la figura 3 se representa la cartografía del reparto de teselas adscritas a los distintos TUC en 1956 y 2014 respectivamente. Los datos numéricos se recogen en la tabla 3. Destacan el cambio de proporción total arbolada, que pasa del 48,1\% al 63,5\%, con una densificación evidente (del 19,0\% al 46,6\% en el rango de mayor espesura). Ruiz Flaño et al. (2010) ya mostraron valores similares para el conjunto de los bosques: del 33,6\% (1956) al 67,5\% (2001). 
Tabla 2. Reparto superficial del arbolado en sus diferentes rangos de cobertura (mayor del $35 \%$ ) en los sectores septentrional, central y meridional de la subcomarca de Camero Nuevo

\begin{tabular}{lclrc}
\hline & $\begin{array}{c}\text { Superficie } \\
\text { ocupada (ha) } \\
\text { en Camero } \\
\text { Nuevo }\end{array}$ & $\begin{array}{c}\text { Superficie ocupada } \\
\text { (ha) en sectores }\end{array}$ & $\begin{array}{c}\text { Porcentaje de la } \\
\text { superficie con } \\
\text { respecto al total }\end{array}$ \\
\hline Bosques densos (Fcc: 65-100\%) & $9.852,48$ & Sur & $4.656,14$ & 47,26 \\
& & Centro & $5.013,87$ & 50,89 \\
& & Norte & 182,47 & 1,85 \\
\hline Arbolado abierto dominante & $11.741,34$ & Sur & $4.273,69$ & 36,40 \\
(Fcc: $50-65 \%)$ & & Centro & $5.750,99$ & 48,98 \\
& & Norte & $1.716,66$ & 14,62 \\
\hline Arbolado abierto no dominante & $3.387,77$ & Sur & 648,14 & 19,13 \\
(Fcc: $35-50 \%)$ con predominio & & Centro & $1.548,40$ & 45,71 \\
de matriz no arbolada & & Norte & $1.191,23$ & 35,16 \\
\hline
\end{tabular}

Fuente: elaboración propia.

Tabla 3. Reparto superficial de varios TUC (tipos de uso y cubierta) en Camero Nuevo en 1956 y en 2014, con subtipos específicos considerados en este estudio ordenados de mayor valor (B / arbolado denso) a menor valor (zonas urbanas o urbanizadas)

\begin{tabular}{|c|c|c|c|c|c|}
\hline TUC & Subtipo & 1956 (ha) & 2014 (ha) & $\begin{array}{c}\text { Porcentaje } \\
1956\end{array}$ & $\begin{array}{l}\text { Porcentaje } \\
2014\end{array}$ \\
\hline \multirow[t]{3}{*}{ Bosques (B) } & Arbolado denso (Fcc $>65 \%)$. & $9.852,6$ & $24.219,3$ & 19,0 & 46,6 \\
\hline & Arbolado abierto dominante (Fcc: 50-65\%). & $11.741,5$ & $7.827,1$ & 22,6 & 15,1 \\
\hline & $\begin{array}{l}\text { Arbolado abierto no dominante, no adehe- } \\
\text { sado, con predominio de matriz no arbola- } \\
\text { da (Fcc: } 35-50 \%) \text {. }\end{array}$ & $3.387,8$ & 930,8 & 6,5 & 1,8 \\
\hline \multirow[t]{2}{*}{ Galerías arbóreas } & Galería arbórea \pm continua. & 81,2 & 152,7 & 0,2 & 0,3 \\
\hline & Galería arbórea discontinua. & 167,4 & 95,9 & 0,3 & 0,2 \\
\hline \multirow[t]{4}{*}{ Matorrales } & $\begin{array}{l}\text { Matorral } \pm \text { puro con inclusiones de arbola- } \\
\text { do (Fcc: } 15-35 \% \text { ) en distribución múltiple } \\
\text { (rodales, líneas/setos, pies dispersos). }\end{array}$ & $5.332,2$ & $5.852,3$ & 10,3 & 11,3 \\
\hline & $\begin{array}{l}\text { Matorral } \pm \text { puro con arbolado disperso } \\
(\mathrm{Fcc}<15 \%) \text {. }\end{array}$ & $2.849,6$ & 855,0 & 5,5 & 1,6 \\
\hline & $\begin{array}{l}\text { Matorral sensu lato (cubiertas mixtas de } \\
\text { leñosas y herbáceas) con inclusiones } \\
\text { de arbolado (Fcc: } 15-35 \% \text { ) en distribu- } \\
\text { ción múltiple (rodales, líneas/setos, pies } \\
\text { dispersos). }\end{array}$ & $4.128,6$ & $4.729,6$ & 7,9 & 9,1 \\
\hline & $\begin{array}{l}\text { Matorral sensu lato (cubiertas mixtas } \\
\text { de leñosas y herbáceas) con arbolado } \\
\text { disperso (Fcc }<15 \% \text { ). }\end{array}$ & $1.353,4$ & $1.122,9$ & 2,6 & 2,2 \\
\hline Repoblaciones & & 0,0 & 996,5 & 0,0 & 1,9 \\
\hline
\end{tabular}


Tabla 3. Reparto superficial de varios TUC (tipos de uso y cubierta) en Camero Nuevo en 1956 y en 2014, con subtipos específicos considerados en este estudio ordenados de mayor valor (B / arbolado denso) a menor valor (zonas urbanas o urbanizadas) (continuación).

\begin{tabular}{|c|c|c|c|c|c|}
\hline TUC & Subtipo & 1956 (ha) & 2014 (ha) & $\begin{array}{l}\text { Porcentaje } \\
\quad 1956\end{array}$ & $\begin{array}{l}\text { Porcentaje } \\
\quad 2014\end{array}$ \\
\hline \multirow[t]{4}{*}{ Pastos herbáceos } & $\begin{array}{l}\text { Pasto herbáceo } \pm \text { puro/pastizal leñoso } \\
\text { bajo o mezcla íntima de herbáceas con } \\
\text { participación apreciable o presumible de } \\
\text { leñosas, en entremezcla o micromosaico o } \\
\text { matriz mixta. Con inclusiones de arbolado } \\
\text { (Fcc: } 15-35 \% \text { ) en distribución múltiple } \\
\text { (rodales, líneas/setos, pies dispersos). }\end{array}$ & 337,9 & 549,3 & 0,7 & 1,1 \\
\hline & $\begin{array}{l}\text { Pasto herbáceo } \pm \text { puro/pastizal leñoso } \\
\text { bajo o mezcla íntima de herbáceas con } \\
\text { participación apreciable o presumible } \\
\text { de leñosas (matorral), en entremezcla o } \\
\text { micromosaico o matriz mixta. Con arbola- } \\
\text { do disperso (Fcc }<15 \%) \text {. }\end{array}$ & 635,2 & 834,0 & 1,2 & 1,6 \\
\hline & $\begin{array}{l}\text { Pasto herbáceo s. I. con inclusiones de } \\
\text { arbolado (Fcc: } 15-35 \% \text { ) en distribución } \\
\text { múltiple (rodales, líneas/setos, pies dis- } \\
\text { persos). }\end{array}$ & 13,4 & 30,0 & 0,0 & 0,1 \\
\hline & $\begin{array}{l}\text { Pasto herbáceo s. I. con inclusiones de } \\
\text { arbolado (Fcc: } 15-35 \% \text { ) en distribución } \\
\text { múltiple (rodales, líneas/setos, pies disper- } \\
\text { sos). Con arbolado disperso (Fcc < } 15 \% \text { ). }\end{array}$ & 61,1 & 61,1 & 0,1 & 0,1 \\
\hline \multirow[t]{7}{*}{$\begin{array}{l}\text { Roquedos } \\
\text { y canchales }\end{array}$} & $\begin{array}{l}\text { Roquedo y/o canchal predominantes con } \\
\text { matorral y arbolado (Fcc: } 15-35 \%) \text {. }\end{array}$ & 278,6 & 425,1 & 0,5 & 0,8 \\
\hline & $\begin{array}{l}\text { Roquedo y/o canchal predominantes con } \\
\text { matorral y arbolado ( } \mathrm{Fcc}<15 \% \text { ). }\end{array}$ & 517,5 & 204,8 & 1,0 & 0,4 \\
\hline & $\begin{array}{l}\text { Roquedo y/o canchal predominantes con } \\
\text { arbolado (Fcc: } 15-35 \%) \text {. }\end{array}$ & 88,5 & 202,2 & 0,2 & 0,4 \\
\hline & $\begin{array}{l}\text { Roquedo y/o canchal predominantes con } \\
\text { arbolado (Fcc }<15 \% \text { ). }\end{array}$ & 215,7 & 215,7 & 0,4 & 0,4 \\
\hline & $\begin{array}{l}\text { Roquedo y/o canchal predominantes con } \\
\text { matorral (Fcc matorral > 65\%). }\end{array}$ & 242,6 & 0,0 & 0,5 & 0,0 \\
\hline & $\begin{array}{l}\text { Roquedo y/o canchal predominantes con } \\
\text { matorral (Fcc matorral: } 35-65 \%) \text {. }\end{array}$ & 657,0 & 860,7 & 1,3 & 1,7 \\
\hline & $\begin{array}{l}\text { Roquedo y/o canchal predominantes con } \\
\text { matorral (Fcc matorral: } 15-35 \%) \text {. }\end{array}$ & 388,7 & 301,6 & 0,7 & 0,6 \\
\hline Cultivos agrícolas & & $9.314,4$ & 812,1 & 17,9 & 1,6 \\
\hline Masas de agua & & 33,2 & 325,0 & 0,1 & 0,6 \\
\hline $\begin{array}{l}\text { Zonas urbanas } 0 \\
\text { urbanizadas }\end{array}$ & & 293,0 & 367,3 & 0,6 & 0,7 \\
\hline
\end{tabular}

Fuente: elaboración propia. 
Figura 3. Distribución de tipos de uso y cubierta (TUC) en Camero Nuevo en los años 1956 (a) y 2014 (b)
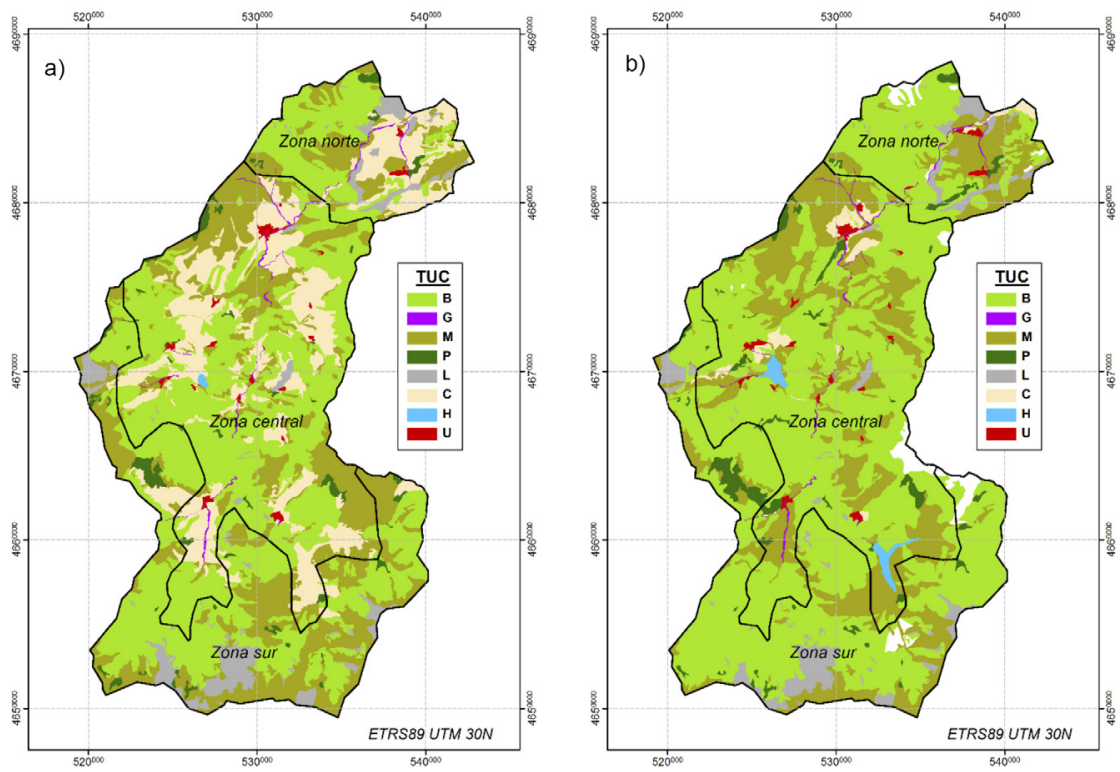

B: bosques; G: galerías arbóreas; M: matorrales; P: pastos herbáceos; L: roquedos y canchales; C: cultivos agrícolas; $\mathrm{H}$ : masas de agua; $\mathrm{U}$ : zonas urbanas o urbanizadas

Fuente: elaboración propia.

Con los datos del análisis diacrónico cuantitativo se muestra que hay bosques que no son tan antiguos como puede pensarse o que se han densificado, lo que permite la activación de otras tendencias dinámicas (como los pinares del sur de la comarca, una vez establecidos en espesura, que van siendo paulatinamente desplazados por hayedos actualmente intercalados) (figura 4).

Mediante la superposición de las capas de diversos TUC de 1956 y 2014 se detectaron los distintos tipos de cambios recientes sucedidos en la comarca. Como ya se ha indicado (apartado 1) este fue un período fundamental en los procesos de transformación del paisaje. En la figura 5 se representan las valoraciones de las transformaciones de varios TUC de forma cartográfica. Estas valoraciones se basan en el número de categorías (TUC y subtipos) en la tabla 3 (filas en esta tabla) entre los asignados en ambas fechas de estudio para cada tesela. Predominan los cambios progresivos (valores positivos, cambio hacia arriba en la tabla 3) y las estabilizaciones. Ello muestra que la expansión y la densificación del arbolado ya venía produciéndose en la primera mitad del siglo Xx. La tendencia se incrementó con la fuerte disminución de los aprovechamientos de pastos y de leñas a partir de la década de 1960. 
Figura 4. Pinares (Pinus sylvestris) con intercalaciones de hayedos (Fagus sylvatica) en las laderas del valle del Alto Iregua

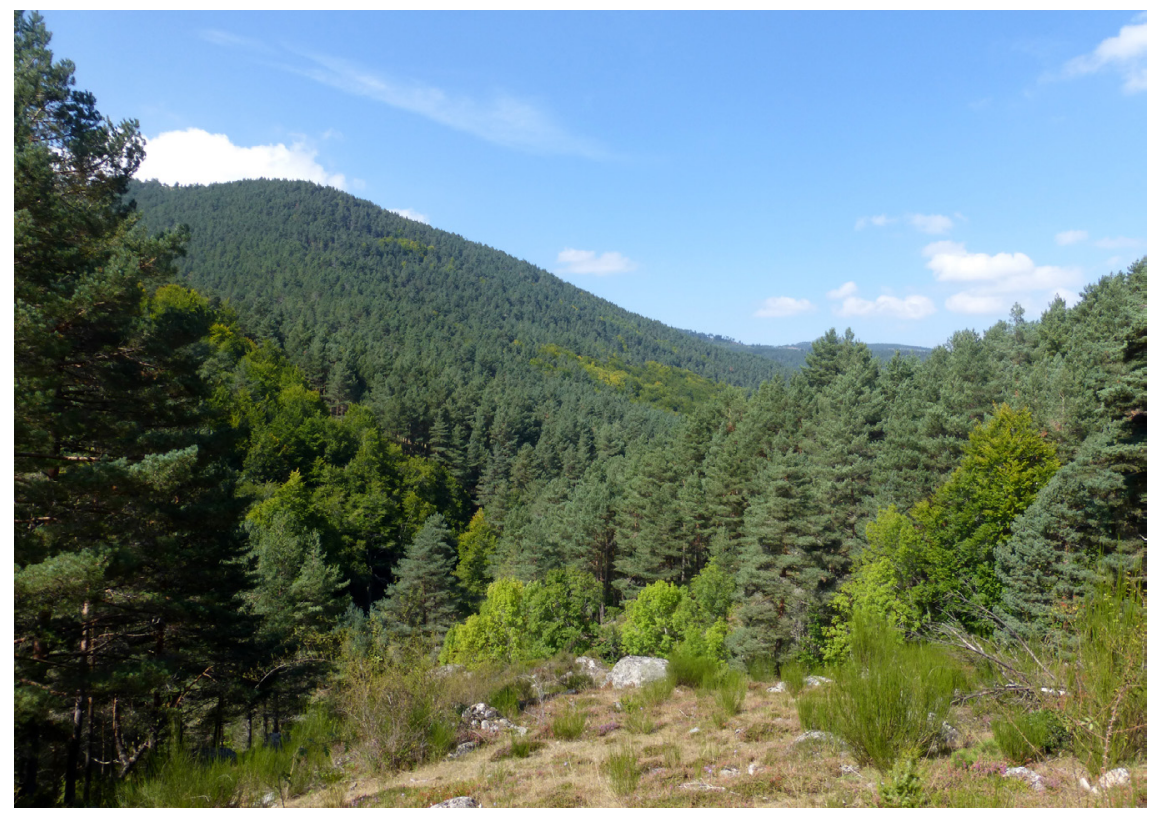

Fuente: autores.

El 74,2\% de los bosques actuales procede de arbolados de baja espesura, mientras que un 22,3\% de ellos se ha originado sobre teselas que en 1956 sustentaban matorrales (con eventuales inclusiones de arbolado) y un 3,4\% desde parcelas agrícolas. El 63,6\% de los bosques densos (Fcc > 65\%) proceden de arbolado abierto dominante (Fcc 35-65\%).

\section{Discusión}

El estudio científico de los paisajes de épocas pasadas viene condicionado por la disponibilidad de fuentes de información y de metodologías apropiadas para el análisis geográfico. Por ello, hasta mediados del siglo xx no se pudo hacer un análisis preciso y objetivo de los paisajes que existían en un territorio y por lo tanto tampoco se podía hacer un seguimiento de la evolución entre dos fechas. Esta situación terminó con la obtención sistemática de fotografía aérea y con imágenes desde satélites con una cobertura completa y con frecuencias cada vez mayores.

La falta de imágenes captadas desde el aire reduce los análisis de los paisajes a las áreas y a las fechas de las que existe documentación territorial (mapas 
Figura 5. Valoración de los cambios de TUC en Camero Nuevo entre 1956 y 2014. Con valores positivos, cambios progresivos de formaciones vegetales (hacia mayor categoría estructural). Las clases más frecuentes son las estabilizaciones (un 43,8\%) y las progresiones de amplitud 1 (un $23,9 \%$ ) y 4 (un $13,9 \%$ )

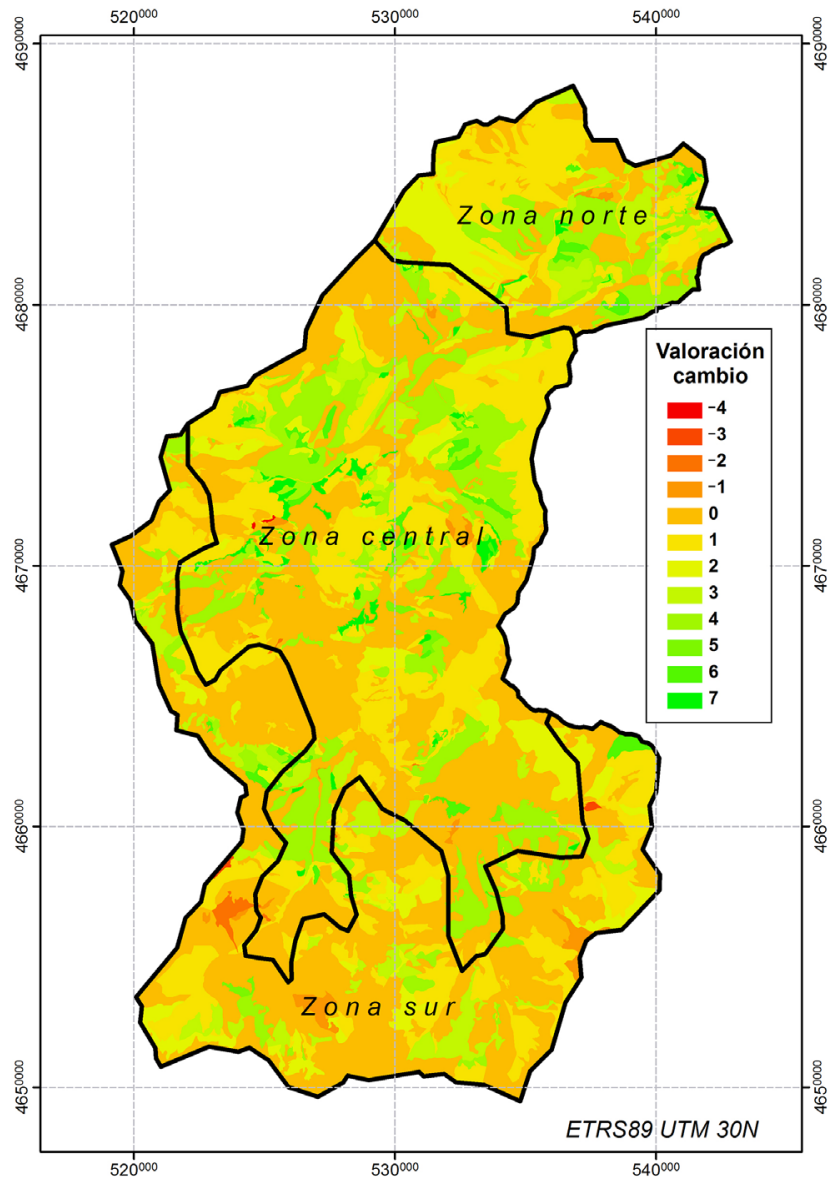

Fuente: elaboración propia.

catastrales, censos poblacionales, inventarios forestales, etc.). Ante esta realidad de disponibilidad informativa de datos tan desigual y heterogénea, se ha optado por escindir el estudio en dos etapas: antes y después de la disponibilidad de fotografía aérea.

En la primera parte se han identificado los factores que han determinado la estructura de los paisajes hasta la mitad del siglo xx y con ellos se ha interpretado la estructura de 1956. En la segunda se comparan los patrones 
espaciales de los paisajes de 1956 y 2014. Por último se analizan y se discuten las consecuencias de la creciente socialización del pensamiento ambientalista.

\subsection{Carácter cultural de los paisajes previos al análisis estructural cuantitativo}

La documentación geográfica, demográfica, etnográfica, ecológica, toponímica (López Leiva, 2016) y socioeconómica anterior a 1956 nos sugiere que el patrón espacial era característico de un paisaje cultural directamente modelado por la actividad ganadera que, con carácter dominante, se ha mantenido hasta el siglo pasado. No es aventurado afirmar que desde hace mil años la presión ganadera ha creado y mantenido unas estructuras del paisaje ecológicamente degradadas, económicamente rentables y socialmente aceptadas.

Los paisajes previos a 1956 son el resultado de los factores que los modelaron en las épocas pretéritas. Su existencia activa se ve reflejada en la estructura y en su patrón espacial de los paisajes evaluados cuantitativamente en la fotografía aérea. La presencia de matorrales, pastizales y bancales es prueba de que durante varios siglos el hombre ha mantenido su actividad agropecuaria de forma continuada, conformando unos paisajes culturales milenarios.

En la foto aérea de 1956, además de los elementos teselares de origen muy antiguo, se detectan otros más recientes con una presencia todavía muy baja. No obstante su poca extensión, las nuevas teselas incorporadas generan una mayor diversificación teselar de los paisajes. Podemos considerar que la diversidad estructural es un buen indicador del grado de desculturización de los paisajes de Camero Nuevo por abandono generalizado de las actividades antrópicas tradicionales y el desarrollo localizado de otras nuevas que provocan la aparición de componentes teselares y lineales renovados (naturalización).

El proceso de transformación de teselas por abandono de sus usos tradicionales se puede calificar de desculturización del paisaje. Sus causas más frecuentes son: $a$ ) el cambio en las condiciones socioeconómicas, rompiendo el equilibrio alcanzado para lograr la sostenibilidad del paisaje; $b$ ) la aparición de nuevos usos en el ámbito socioeconómico, que incrementan las rentabilidades económicas y/o las demandas sociales, de modo que se logre otro tipo de equilibrio sostenible, o $c$ ) que, de manera coyuntural y con un beneficio suprapaisajístico, se impongan cambios a nivel ecosistémico produciendo una pérdida de composición y/o configuración. Durante este proceso se van borrando las huellas de los usos tradicionales con una velocidad variable en función de las condiciones ecológicas generales y del grado de degradación que han alcanzado.

El proceso de aparición de nuevos usos del territorio es mucho más rápido, hasta el punto de ser calificado como súbito. Su extensión superficial tiende a ser reducida e inversamente proporcional a la intensidad degradante del nuevo uso.

\subsection{Los paisajes actuales}

En el modelo espacial del paisaje de 2014 se reflejan ya las consecuencias del desplome demográfico rural del siglo xx. Junto al retroceso en la actividad 
Figura 6. Pinillos de Cameros. Enebrales (Juniperus communis) y lasto-timo-aliagares (con Genista scorpius dominante) en el entorno de la población, colonizando laderas en que el pastoreo permanente fue más intenso

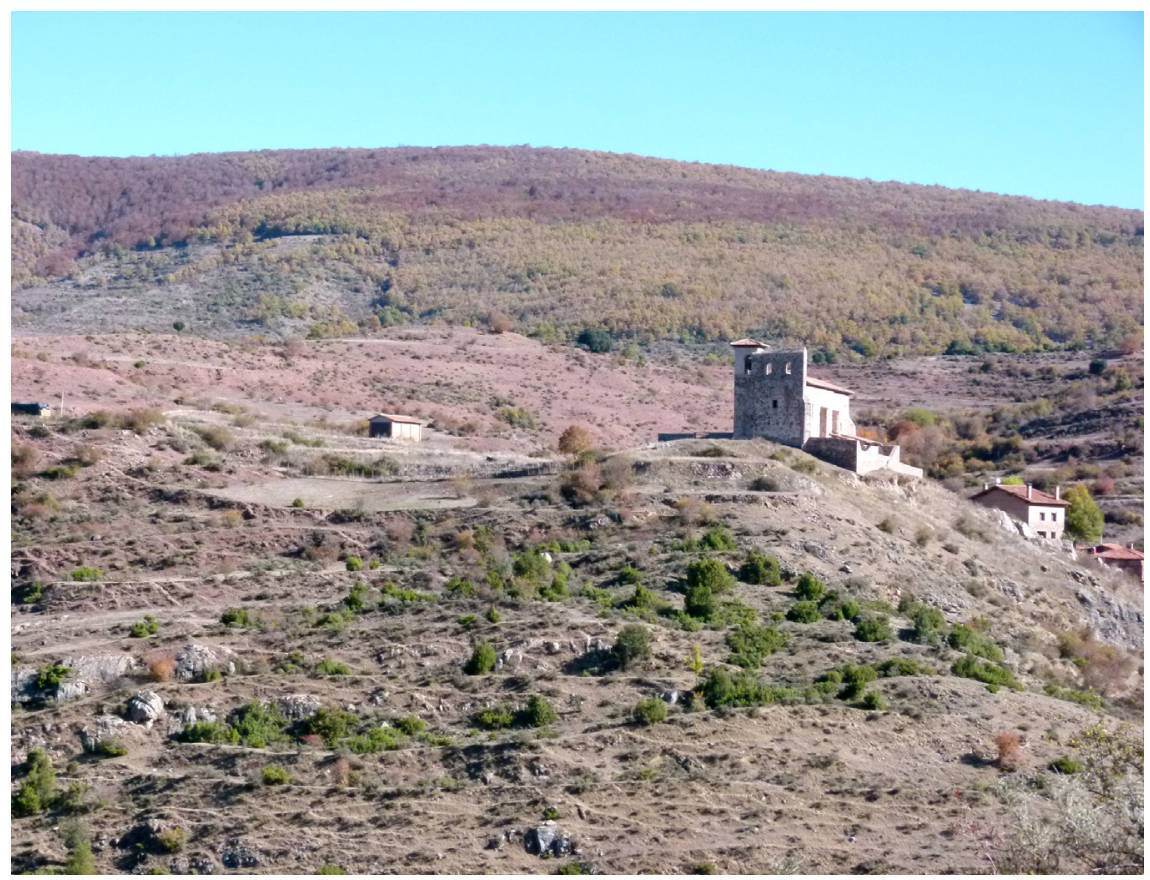

Fuente: autores.

ganadera caen también los aprovechamientos agrícolas y se produce el hundimiento económico definitivo de las montañas ibéricas, que trae como consecuencia el éxodo migratorio a partir de las décadas de 1950 y 1960, así como el envejecimiento de la población remanente. Con la menor carga ganadera, que además fue pasando a extensiva de vacuno, se produjo la lignificación de los pastos y la densificación y extensión de los matorrales (figura 6), consecuencia de la mengua de extracción de leñas, ya no usadas como combustible doméstico.

Los pastizales abandonados, antes sometidos a quemas periódicas, dieron paso en primera instancia a aulagares (Genista scorpius) o biercolares (matorrales bajos de Erica y Calluna), en los que la composición, la talla, la densidad y la distribución vienen determinados por el régimen previo de uso. Los cambios en la intensidad de los aprovechamientos también indujeron la expansión del arbolado (figura 7).

Como veremos y ya mostraron Ruiz Flaño et al. (2010) y Lasanta (2010), desde la década de 1950 se ha consolidado la tendencia a la recolonización del arbolado, particularmente rápida en esta subcomarca comparada con su adya- 
Figura 7. Expansión de robledales en laderas previamente matorralizadas y parcialmente abancaladas, antaño pastos y rodales de monte bajo para extracción de leñas y carboneo. Pinillos de Cameros

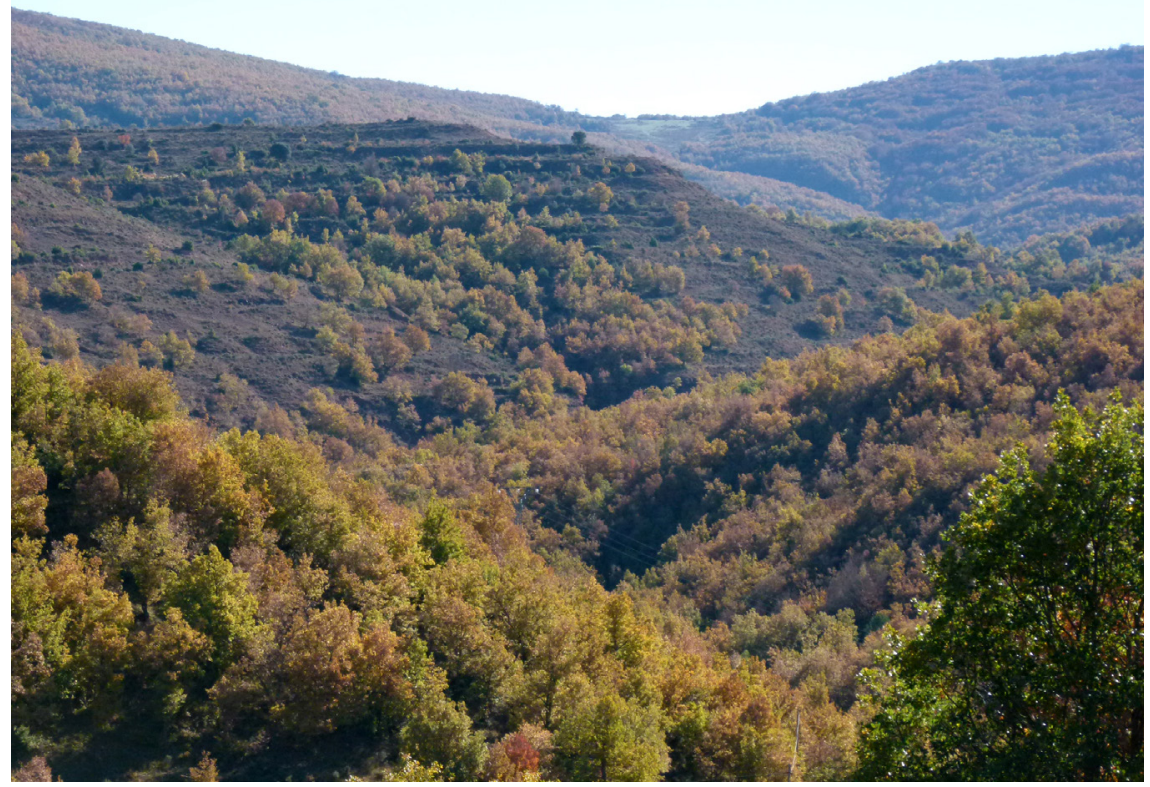

Fuente: autores.

cente oriental (Camero Viejo), que es de carácter general más mediterráneo. También se repoblaron algo más de 3.000 hectáreas en todo Cameros por parte de la Administración forestal (Fernández Aldana, 2015). En definitiva, la fisonomía del paisaje es distinta de la que se hubiera podido contemplar hace solo un siglo y medio, con cambios especialmente rápidos y patentes a partir de la década de 1960. En todo caso, en los montes de utilidad pública, el aprovechamiento ordenado, que garantiza la persistencia del vuelo arbóreo, ha sido un hecho desde el siglo XIx y sigue siendo fuente de riqueza para la población rural. A lo largo del siglo xx y hasta la actualidad, la Administración forestal ha salvaguardado montes municipales incluidos en el catálogo de los Montes de Utilidad Pública de La Rioja, aún en plena vigencia. Principalmente en la mitad meridional, constituyen el régimen de propiedad casi exclusivo y la base de los espacios naturales, pues su ordenación es instrumento de conservación.

En relación con el patrimonio cultural, muchos montes arbolados son objeto de diversos aprovechamientos sostenibles (madera, caza) ya arraigados, y otros que han resurgido en los últimos decenios (por ejemplo, las recolecciones de setas), aparte del uso de los pastos remanentes intercalados. 


\subsection{Discusión en torno al paisaje y su patrimonialización por parte de sociedades urbanas}

De forma general podemos plantear el contraste de aproximaciones al paisaje actual. Los procesos que han tenido lugar en los paisajes culturales tradicionales de Camero Nuevo han desembocado en un mosaico de «nuevas» cubiertas vegetales que induce en sus visitantes ocasionales la falsa apariencia de inmutabilidad. En casos como el que nos ocupa, el paisaje, que es concepto espacial y temporal, puede ser percibido con visión admirativa basada en atributos estéticos o en un enfoque vagamente ambientalista. Entre los habitantes del medio urbano es frecuente la conciencia de que pastoreo, trashumancia y Cameros están íntimamente relacionados, pero con una aproximación imprecisa a los factores ecológicos y los cambios sociales. Cuando no se tiene asimilada la historia de la acción humana, se corre el riesgo de que quede desdibujada la interdependencia, incluso la coevolución, entre esta y las transformaciones del entorno natural.

Ciertos tipos de cubierta vegetal son resultado de una presión antrópica moderada o alta, de manera que la desaparición de esta pone en riesgo su persistencia, como es el caso de las acebedas (comunidades de Ilex aquifolium) (figura 8) o muchos tipos de matorral.

En Camero Nuevo la superposición a la ruralidad ancestral de una reciente turistificación de raíz urbana brinda una oportunidad para un nuevo enfoque de los valores patrimoniales basado en un conocimiento más profundo y objetivo de la dinámica y de la multifuncionalidad del paisaje, de manera que queden integradas las miradas actuales y las pretéritas (Martínez de Pisón, 2009).

La urbanización, más allá de la evidente degradación ecológica directa de las áreas que son ocupadas por estructuras ciudadanas, está propiciando un cambio en la percepción de los espacios rurales que han sobrevivido a la revolución industrial de los siglos XIX y xx. Los habitantes urbanos, dado su dominio demográfico, imponen paisajes totalmente organizados funcionalmente para satisfacer las diferentes demandas de bienes y servicios. Como consecuencia de ello, la población rural decrece y sus requerimientos específicos sobre el territorio tienen cada vez una menor demanda social; una demanda que es progresivamente sustituida por unas necesidades de perfil urbano, en cuyo crecimiento indefinido se basa la teórica razón de ser del sistema económico.

Las miradas urbana y rural son generalmente contrapuestas. Frente a la idea idílica de parte de las sociedades urbanas de que la gestión del medio debe consistir en ausencia de intervención, presuponiendo, además, que el paisaje es estable cuando llega a su máxima expresión de naturalidad, los escasos habitantes rurales, que siguen configurando el hábitat humano, tendrán una percepción divergente, más realista, por su experiencia directa de valoración de los recursos (Lasanta y Pascual, 2015).

En esta tesitura deviene una necesidad insoslayable sensibilizar al observador de extracción urbana o «externo» al territorio para que la valoración social 
Figura 8. Acebedas abiertas, con ejemplares dispersos o en pequeños rodales en Villoslada y Montenegro de Cameros, que tuvieron uso ganadero por servir de lugar de refugio, pastoreo y ramoneo. Actualmente hay una clara expansión de espinos caducifolios

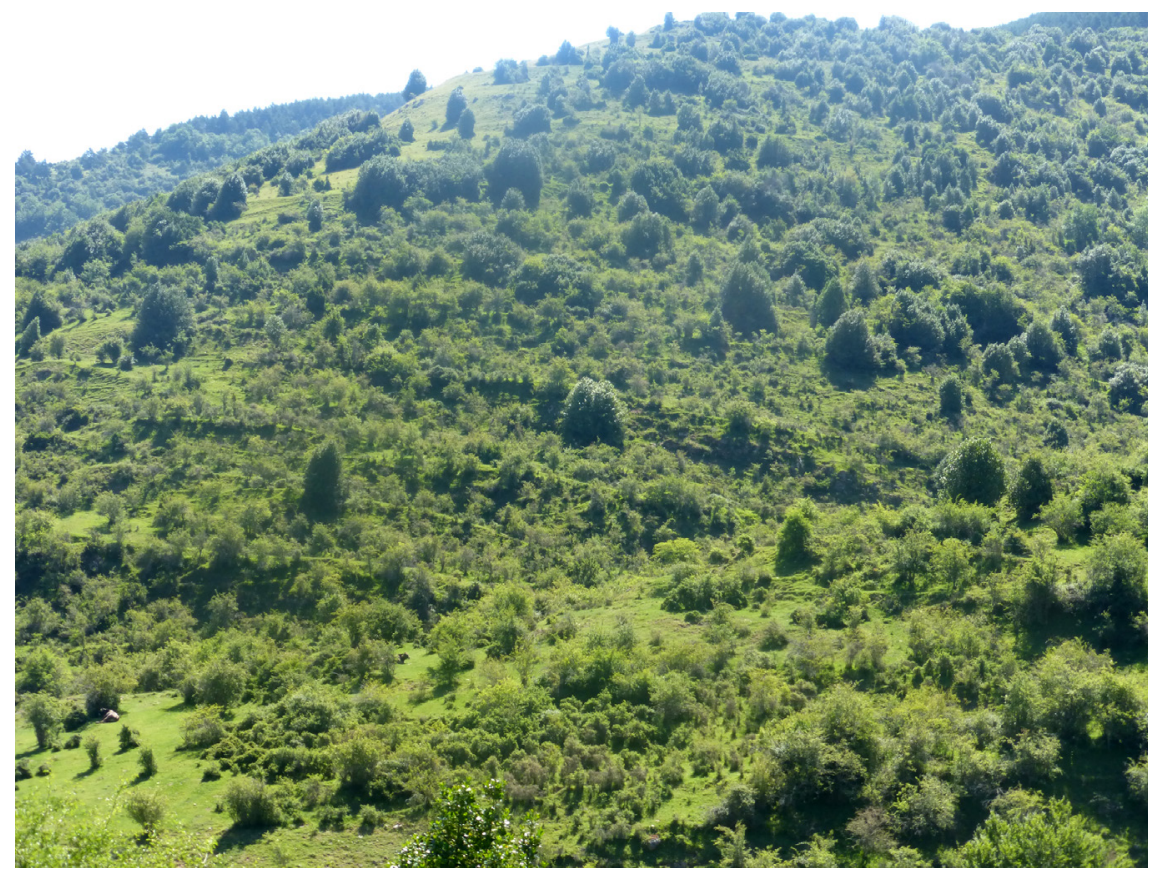

Fuente: autores.

e institucional quede así reforzada y pueda ser más sólidamente transmitida. Este proceso implica el educar la atención de forma racional, envolvente, desde múltiples aproximaciones. Señalamos aquí dos: $a$ ) la que deriva de la interiorización de la historia de los usos y aprovechamientos, su intensidad, duración y recurrencia, como la reseñada en el apartado 3.1, y b) la que se deduce de análisis complementarios, sistemáticos, sobre la evolución diacrónica, incorporando una perspectiva ecológica que trascienda el concepto de paisaje como mero panorama estético-cultural.

Dentro de Camero Nuevo, la Sierra Cebollera es un paradigma de la evolución de la vegetación durante los tres últimos siglos. Se han recuperado los bosques, tanto los de coníferas aciculifolias orófilas (los pinares de Pinus sylvestris ) — que dificultosamente resistieron incendios repetidos y el diente de los herbívoros- como los de frondosas caducifolias o de hoja marcescente, cuyas masas permanecían confinadas a las zonas no pastoreadas (figura 9). La declaración de parque natural en 1995 supuso el afianzamiento de la gestión forestal sostenible, a la que se añadía una progresiva voluntad de divulgación de los valores ambientales. 
Figura 9. Pinares (Pinus sylvestris) desde la divisoria de la Sierra de Fregüela, al SO de la comarca. En época de auge ganadero, la presencia de pinos, refugiados en lugares más inaccesibles, debió de ser en parte vestigial. Luego vino su colonización en zonas antes dedicadas a los pastos herbáceos. Con todo, quedaban pinares dominantes en algunos términos, como el de Villoslada, según citaba Madoz en su Diccionario (1845-1850).

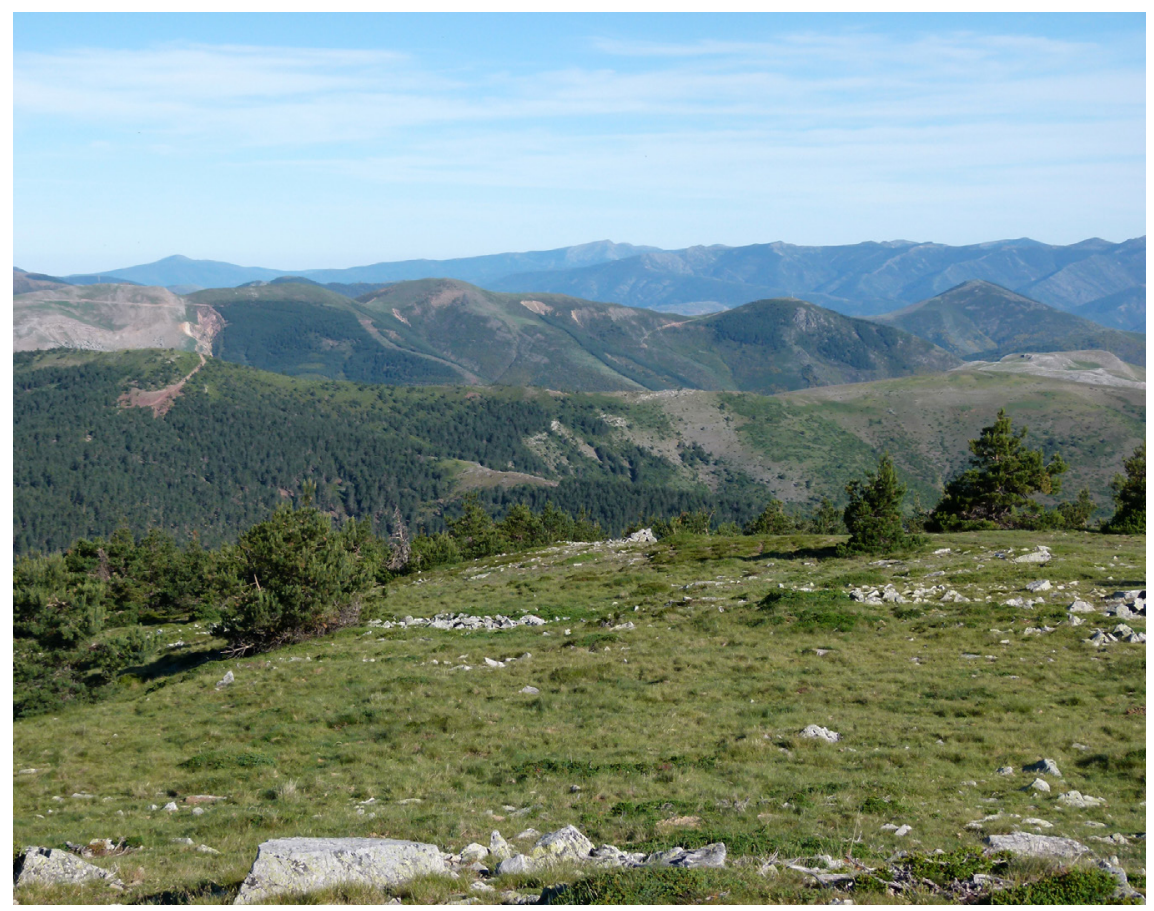

Fuente: autores.

Puede hablarse de un «redescubrimiento» contemporáneo del paisaje de Cameros, puesto que sobre todo desde finales del siglo xx se afianza, con una tendencia creciente, su uso ecoturístico. En el Parque Natural de la Sierra Cebollera se estima un volumen de 125.000 visitantes al año, con más del $50 \%$ de riojanos, sobre todo de la ciudad de Logroño, y foráneos, entre los que destacan vascos y madrileños (Gobierno de La Rioja, 2015). Se asiste, pues, a la revalorización de un paisaje de elevado interés ecológico, estético e histórico. Así, de «lugar de acción» y fuente de subsistencia, como en siglos pasados, Camero Nuevo ha pasado a ser escenario para el uso ambiental, manteniéndose los aprovechamientos ordenados en montes comunales. En los espacios naturales protegidos cameranos (parque natural, LIC de la Red Natura 2000), se reconocen en el tapiz vegetal unos valores ecológicos que se agregan a los del patrimonio cultural inmaterial ganadero, hoy menos conspicuo. Se plantea entonces el fomento del turismo ecológico sin que este suponga la alteración sustancial del modo de vida de los habitantes ni de sus tradiciones rurales. 
La cuestión subyacente es la necesidad de profundizar en el conocimiento de qué se tiene en la actualidad y en su caso qué se está conservando en paisajes secularmente modelados por la acción humana, dado que, como expresan Silva et al. (2018), "las apropiaciones identitarias y los reconocimientos institucionales que llevan a cabo las sociedades se entienden siempre desde su actualidad». No obstante, debe calar la idea de que los paisajes y sus elementos son cambiantes. Las cubiertas vegetales no quedan «congeladas» en el tiempo y las formas de transformación son múltiples y pueden darse en sentido progresivo o regresivo; a partir de un cierto estadio, hay un haz de trayectorias de cambio, evoluciones cíclicas, saltos de distinta envergadura. El conjunto de todas las cubiertas identificables constituye así una red o complejo evolutivo (Ruiz de la Torre, 1990). Las diferentes teselas de vegetación como elementos de los paisajes están más o menos alejadas de los óptimos potenciales teóricos (clímax) para cada ámbito climático y que podemos imaginar semejantes a las comunidades con intervención humana directa o con esta muy discreta. Pero ese estadio es solo hipotético, cuando no ilusorio, si, al hablar de potencialidad, prescindimos de la historia de los usos. Para pronosticar cuál es la etapa de mayor madurez posible se necesitarían plazos largos que permitieran refutar las teorías con observaciones contrastadas, difíciles de plantear en situación de coevolución del tapiz vegetal y de las poblaciones humanas. Una situación que, precisamente, hace del paisaje un bien patrimonial. Es preferible entonces usar el concepto de vegetación más idónea (fittest vegetation, según Ingegnoli, 2015), en el sentido de más ajustada a los recursos ambientales y que es producto de la historia previa.

La sostenibilidad de las masas forestales requiere valorar el delicado equilibrio entre la tendencia natural a la evolución progresiva y los diferentes episodios estabilizadores que la bloquean. Es decir, si se quieren conservar teselas en su estado actual, debe mantenerse el aprovechamiento que las ha hecho posibles, con su intensidad y duración, y considerando también una eventual reducción de la actividad humana.

Las fronteras entre paisajes naturales y culturales son difusas. La restauración pasiva o la regeneración espontánea por reducción de la acción humana es el fenómeno que desemboca en la expansión incipiente del arbolado (figura 10) o de los matorrales previamente existentes de forma minoritaria en terrenos de pastizales herbáceos, pero ello puede enmascarar una realidad previa, antropizada, que hay que descifrar a partir de indicadores y herramientas que permitan el análisis temporal.

El incremento de superficie de arbolado (masas, rodales, pies dispersos) indica mayor progresión ecológica por aumento de la "capacidad biológica territorial» (Ingegnoli, 2015), y el mismo significado tiene la proliferación de matorrales en áreas previamente desprovistas de vegetación leñosa o en cultivos. Para estabilizar deliberadamente los pastos y matorrales sin el uso que les dio origen, sería precisa la práctica de desbroces y quemas en lugares donde actualmente no hay ya carga ganadera apreciable, lo cual es dudosamente viable desde el punto de vista socioeconómico e incluso teniendo en cuenta los principios de la teoría ecológi- 
Figura 10. En Cameros, Acer monspessulanum es una especie arbórea típicamente asociada a la colonización espontánea de antiguas zonas de pasto abancaladas, en las que sobre un fondo de aulagares (Genista scorpius) sobreviene la dispersión de enebros (Juniperus communis) y de los rodales de esta especie pionera y heliófila. Proximidades de Almarza de Cameros, cerca de dehesas municipales de robles y hayas

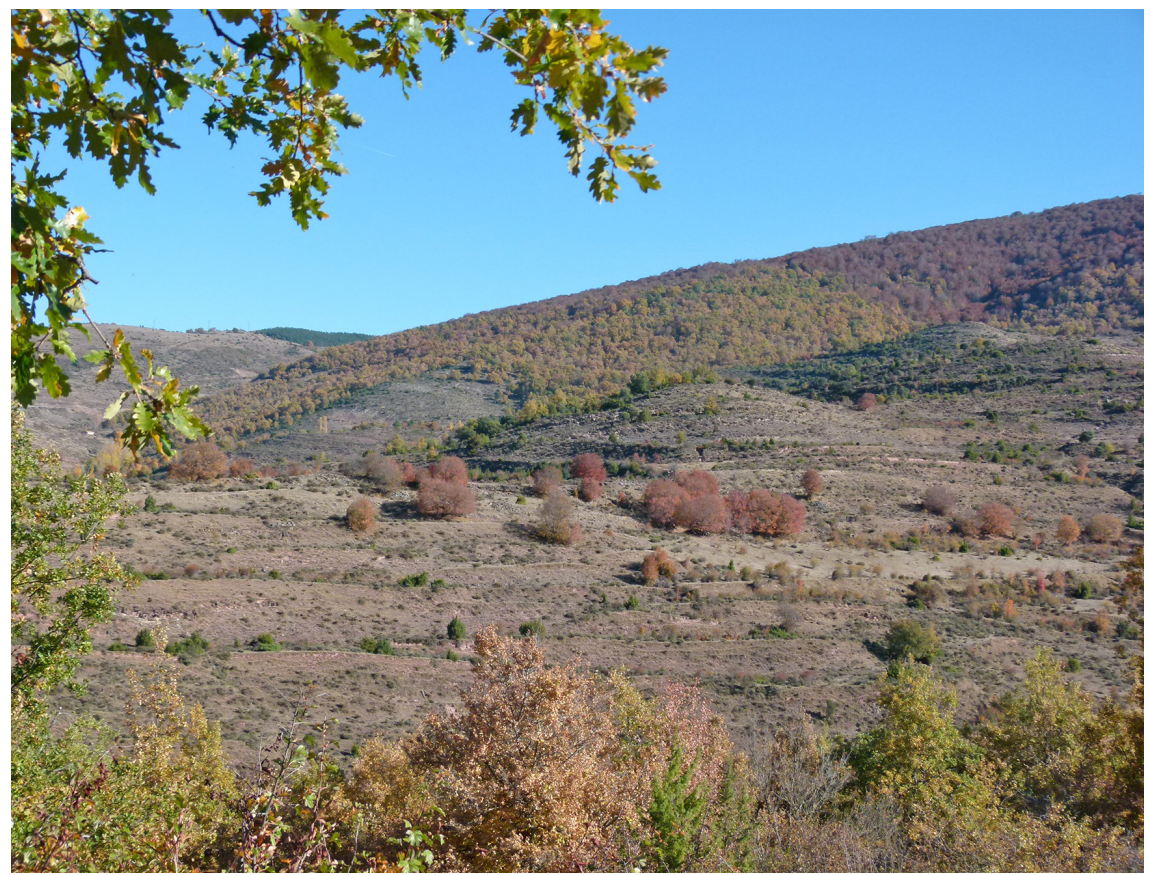

Fuente: autores.

ca. La heterogeneidad interna de los paisajes debería potenciarse manteniendo muestras significativas, tanto de bosques como de otros tipos de formaciones, que contrastan con la aparente monotonía del estrato dominante en masas arboladas monoespecíficas (figura 11). La proliferación del arbolado podría suponer pérdida de diversidad a escala de paisaje (Ruiz Flaño et al., 2010).

La acción humana racionalizada (por ejemplo, mediante la ordenación de montes y las planificaciones) acelera la secuencia de cambios progresivos y es un factor determinante del tejido ecológico (sensu Ingegnoli, 2015). A esa gestión, que garantiza la sostenibilidad de las masas existentes o que planifica la evolución de los bosques creados por repoblación, se añaden las actuaciones selvícolas en las masas generadas por una revegetación natural, colonizadora.

Por tanto, una conservación sin gestión directa activaría una dinámica de efectos imprevisibles, sin que tuvieran repercusión en la estabilización de las poblaciones rurales y la creación de riqueza, fundamental para que los espacios hoy valorados por los visitantes estacionales se mantengan en un estado favorable de conservación. 
Figura 11. Matorrales de leguminosas retamoideas (Genista florida y Cytisus scoparius) entremezclados con espinares caducifolios y pastos herbáceos mesófilos con biercolares salpicados. Contrastan con la homogeneidad escénica de las masas de pinar de las laderas del fondo

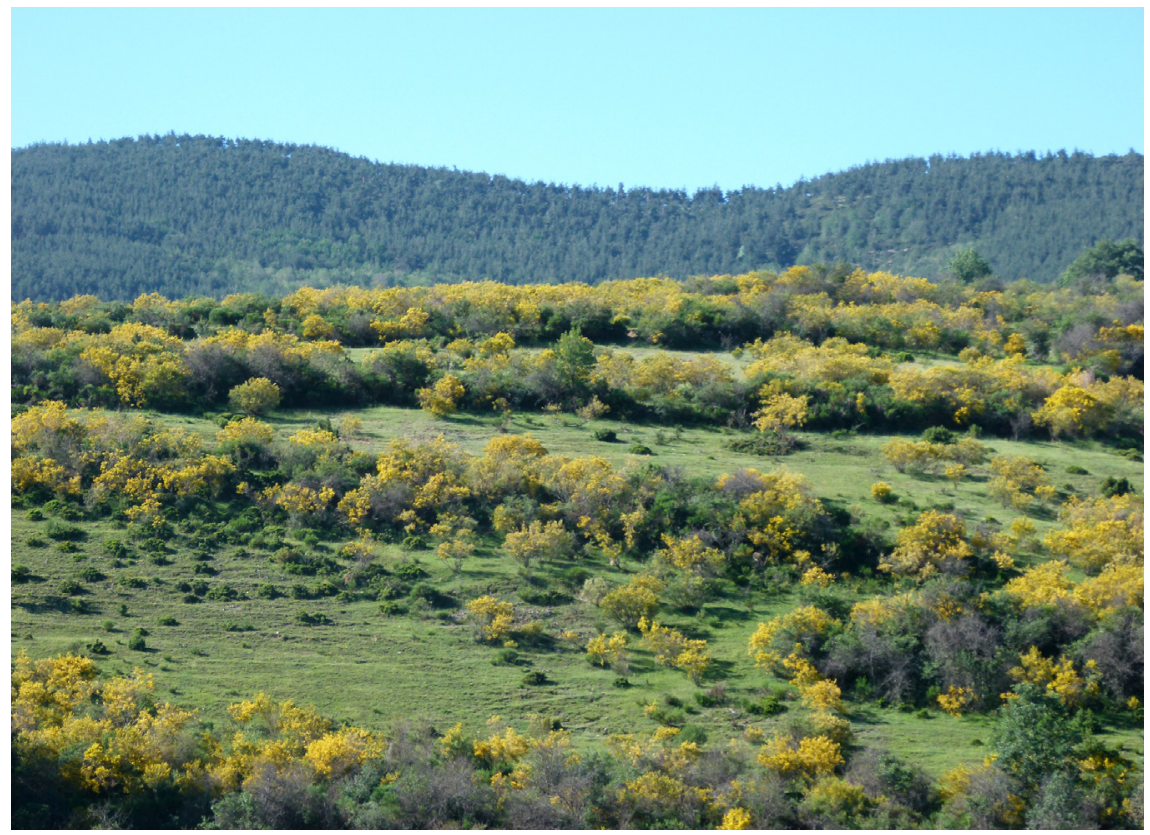

Fuente: autores.

\section{Conclusiones}

Se ha constatado y evaluado la existencia de una dinámica paisajística caracterizada por la progresiva reducción de los elementos ecosistémicos matriciales dominantes de los paisajes culturales tradicionales y la aparición de nuevos componentes surgidos en el último siglo. Estos son consecuencia tanto del declive de las actividades agropecuarias milenarias como del incremento de nuevas actividades que tratan de satisfacer las demandas de la sociedad española actual de nuevos bienes y servicios.

Los paisajes rurales actuales son eclécticos genéticamente, variados estructuralmente, desequilibrados funcionalmente e inestables dinámicamente. Se trata de antiguos paisajes culturales con diverso grado de alteración ecológica según las tres zonas en las que se estructura el Camero Nuevo. Son el resultado de un aprovechamiento continuo de recursos naturales con intensidad variable y objetivos múltiples, que obligan a que los gestores territoriales tengan la visión holística y transdisciplinaria que aporta la ecología del paisaje (Forman y Godron, 1986; Naveh, 1994). Su interacción es esencial para la gestión sostenible. 
En 2014 ya ha desaparecido la mayor parte de los terrenos agrícolas existentes en 1956 por matorralización, y muchos matorrales se han arbolado, bien por procesos naturales de sucesión secundaria tras el cese de actividades ganaderas, bien por reforestaciones localizadas. La transformación hacia una economía de libre mercado provocó el abandono de los cultivos de rentabilidad marginal potenciando los flujos migratorios hacia los núcleos urbanos, tanto nacionales como extranjeros. El declive poblacional redujo los aprovechamientos ganaderos extensivos de ovino e incrementó los más sedentarios de vacuno.

Disminuida la población rural, cambian los actores del paisaje, puesto que se combinan los habitantes rurales autóctonos, los visitantes turísticos y los urbanos de segunda residencia. Esta composición demográfica hace que una parte significativa de la actividad económica de la comarca gravite en torno al turismo rural en los paisajes culturales y al turismo ecológico en los paisajes más naturales como Sierra Cebollera, en donde se practica la tradicional gestión forestal ordenada y sostenible.

Hay que interrogarse sobre si es factible un regreso a los paisajes culturales en toda su antigua extensión. Recrear un paisaje similar al que debió de haber hace siglo y medio nos enfrentaría a la paradoja de reconocer como inviable el mantenimiento de una actividad ancestral ya perdida, que implicaba el uso del fuego y el mantenimiento controlado de estructuras de vegetación de inferior categoría de talla. La situación en 1956, fecha más antigua en cuanto a la disponibilidad de fotografías aéreas de la zona, ya muestra una tendencia de progresión al arbolado que venía teniendo lugar desde finales del siglo XIX, pues una parte considerable de las masas forestales arbóreas son resultado de un cambio de usos.

Ese redescubrimiento, vinculado al conocimiento de la historia precedente, parece indispensable para encontrar una representación equilibrada en el mosaico del paisaje vegetal. Una representación, en definitiva, que garantice la persistencia de muestras características de las distintas unidades de cubierta.

La gestión racional es clave, en todo momento, para una correcta planificación del territorio, más allá del esquematismo inherente a las simplificaciones burdas y utópicas de las realidades rurales. Se debe apuntar prioritariamente a la calidad paisajística del conjunto y de cada uno de sus elementos espaciales. El ciudadano urbano no debe convertirse en un simple esteta, sino que su contemplación del medio natural debe estar configurada por la semiótica del paisaje (Ingegnoli, 2015), es decir, debe tener capacidad para encontrar el sentido de lo que observa e interpreta. En ese aspecto, los propios procesos de cambio pueden constituirse en la base del reconocimiento patrimonial.

El gran reto que paisajes como los de Camero Nuevo plantean a las sociedades urbanas y urbanizadas del siglo xxi es cómo alcanzar un equilibrio entre los tres factores que determinan su sostenibilidad. En claro paralelismo con el papel equilibrador de los tres poderes que Montesquieu definió para un estado de derecho, toda acción humana sobre el espacio rural y natural debe poder contar en su base con idoneidad ecológica, aceptación sociocultural y, asimismo, rentabilidad económica. 


\section{Referencias bibliográficas}

Andrés Cabello, S. (2008). «Por tierras de Cameros». Belezos, 7, 4-13.

Benito González, Á. (2017). Los paisajes de Camero Nuevo (La Rioja) y su valor patrimonial: Análisis diacrónico cuantitativo en el periodo 1956-2014. Trabajo de fin de grado de Ingeniería del Medio Natural dirigido por César López Leiva y Sergio González Ávila. Universidad Politécnica de Madrid. ETSI Montes, Forestal y del Medio Natural.

Díaz-Fernández, P.; Manuel Valdés, C. y Gil Sánchez, L. (2004). La transformación histórica del paisaje forestal en La Rioja. Madrid: Ministerio de Medio Ambiente.

Elías Pastor, J.M.; Elías Pastor, L.V. y Grande Ibarra, J. (1992). Cuadernos de la Trashumancia 4: Alto Macizo Ibérico. Madrid: ICONA.

Elías Pastor, L.V. y Muntión, C. (1989). Los pastores de Cameros. Logroño: Gobierno de La Rioja / Ministerio de Agricultura, Pesca y Alimentación.

Fernández Aldana, R. (2015). Memoria del Mapa de los bosques de La Rioja. Logroño: Gobierno de La Rioja.

Gobierno de la Rioja (2015). Memoria de los 20 años de la creación del Parque Natural de la Sierra de Cebollera. Logroño.

Goerlich Gisbert, F.; Ruiz González, F.; Chorén Rodríguez, P. y Albert Pérez, C. (2015). Cambios en la estructura y localización de la población: Series homogéneas (1900-2011). Bases de Datos. Bilbao: Fundación BBVA.

Forman, E. y Godron, M. (1986). Landscape Ecology. Nueva York: Wiley.

Gómez-Sanz, V.; Bunce, R.G.H. y Elena-Rosselló, R. (2014). Landscape assessment and monitoring. Forest Landscapes and Global Change: Challenges for Research and Management, 199-226. <http://dx.doi.org/10.1007/978-1-4939-0953-7_8>

González Ávila, S. y Elena Rosselló, R. (2009). «SISPARES: Cartografía nacional del patrón y cambio de los paisajes rurales españoles». Cuadernos de la Sociedad Española de Ciencias Forestales, 29, 15-21.

Icona (Instituto Nacional para la Conservación de la Naturaleza) (1990). Clasificación General de los Montes Públicos, 1859. Madrid, Imprenta Nacional, 1859. Reedición facsímil del ICONA. Madrid.

Ingegnoli, V. (2002). Landscape Ecology: A Widening Foundation. Berlín, Heidelberg; Nueva York: Springer-Verlag.

- (2015). Landscape Bionomics: Biological-integrated Landscape Ecology. Berlín, Heidelberg; Nueva York: Springer-Verlag.

LASANTA, T. (2010). «Evolución regional y dinámica del paisaje en La Rioja (19502010)». Zubia, 28, 49-88.

Lasanta, T. y Errea, M.P. (2001). Despoblación y marginación en la Sierra Riojana. Logroño: Instituto de Estudios Riojanos, $181 \mathrm{p}$.

Lasanta, T. y Pascual Bellido, N.E. (2015). «Percepción y valoración del proceso de revegetación por los actores del territorio: Un estudio preliminar en el Sistema Ibérico». Documents d'Anàlisi Geogràfica, 61 (1), 113-134. <https://doi.org/10.5565/rev/dag.158>

Lasanta, T.; Vicente-Serrano, S.M. y Arnáez, J. (2011). «La revegetación en las montañas españolas: ¿Dejar hacer o intervenir en el territorio?». Geographicalia, 59-60, 199-211.

López Leiva, C. (2016). Onomástica, ecología y territorio: La toponimia de La Rioja como indicador biogeográfico y de la dinámica del paisaje forestal. Tesis doctoral. ETSI Montes, Forestal y del Medio Natural (UPM). 
- (2018). «Los paisajes vegetales de Cameros (La Rioja): La respuesta a variantes del ambiente físico y a la acción humana». En: Molinero, F. y Tort, J. (eds.). Paisajes Patrimoniales de España, II. Madrid: Ministerio de Agricultura, Pesca y Alimentación / Ministerio para la Transición Ecológica, 816-847.

Madoz, P. (1845-1850). Diccionario geográfico-estadístico-histórico de España y sus posesiones de Ultramar. Rioja. Colegio Oficial de Aparejadores de La Rioja- Consejería de Educación, Cultura y Deportes de la Comunidad Autónoma de La Rioja. Gráficas Ochoa (reimpresión). Logroño, 1985.

Martínez de Pisón, E. (2009). Miradas sobre el paisaje. Madrid: Biblioteca Nueva.

Moreno Fernández, J.R. (1996). «La ganadería trashumante en La Rioja 1752-1865: Una revisión bibliográfica y cuantitativa». Brocar, 20, 277-302.

Naveh, Z. (1994). "Interactions of landscapes and cultures». Landscape and Urban Planning, 32, 43-54.

Ruiz de la Torre, J. (1990). Mapa Forestal de España a escala 1:200.000: Memoria General. Madrid: ICONA, Ministerio de Agricultura, Pesca y Alimentación.

Ruiz Flaño, P.; Errea Abad, M.P.; Arnáez Vadillo, J.; Oserín Elorza, M. y Lasanta, T. (2010). «El paisaje del Alto Iregua en los últimos 50 años: Evolución y estructura». Zubia, 28, 31-48.

Silva, R.; Fernández, V. y Mata, R. (2018). «Concepto, ámbito y significado de los paisajes patrimoniales». En: Molinero, F. y Tort, J. (eds.). Paisajes Patrimoniales de España, I. Madrid: Ministerio de Agricultura, Pesca y Alimentación / Ministerio para la Transición Ecológica, 17-38. 